\title{
(Transaction】
}

\section{Effects of Melt-Spinning Speed on Structure Development of Polypropylene Fiber After Necking}

\author{
Naoki Koike*1, Ren Tomisawa*1, Toshifumi Ikaga*1, KyoungHou Kim*1, \\ Yutaka Ohkoshi*1,2,\#, Kazuyuki Okada*3, Hiroyasu Masunaga*4, Toshiji Kanaya*5, \\ Hiroo Katsuta*6, and Yoshitsugu Funatsu*6 \\ ${ }^{* 1}$ Faculty of Textile Science and Technology, Shinshu University, 3-15-1 Tokida, Ueda, Nagano 386-8567, Japan \\ ${ }^{* 2}$ Institute for Fiber Engineering, Shinshu University, 3-15-1 Tokida, Ueda, Nagano 386-8567, Japan \\ ${ }^{* 3}$ Toray Research Center, Inc, 3-3-7 Sonoyama, Otsu, Shiga 520-8567, Japan \\ ${ }^{*}$ Japan Synchrotron Radiation Research Institute, 1-1-1 Kouto, Sayo, Hyogo 679-5148, Japan \\ ${ }^{* 5}$ High Energy Accelerator Research Organization, 203-1 Shirakata, Tokai, Ibaraki 319-1106, Japan \\ ${ }^{* 6}$ Toray Industries, Inc, 4845 Mishima, Shizuoka 411-8652, Japan
}

\begin{abstract}
The effects of melt-spinning speed (400-1200 m/min) on fiber structure development after necking were analyzed by wide-angle X-ray diffraction (WAXD) / small-angle X-ray scattering (SAXS) images taken with the time resolution of 0.19-0.34 ms during continuous drawing under the same drawing stress. Whereas an $a^{*}$-axis oriented crystal and a low-oriented long-period structure was formed at lower speeds, a c-axis oriented crystal and highly oriented long-period structure were formed at higher speed. The long-period structure and low-oriented crystal survived for several hundred microseconds after necking, and after the breakdown of that structure, a highly c-axis oriented long-period structure and mesophase were reconstructed. A longer time was required for the structural change in the fibers spun at lower speed, likely because of stress bearing of the surviving $\mathrm{a}^{*}$-axis oriented crystals.
\end{abstract}

(Received 6 January, 2020; Accepted 24 February, 2020)

\section{Introduction}

Isotactic polypropylene (PP) is a stereoregular polymer first synthesized by Natta et al. at 1954 [1] PP has a crystal polymorphism, which depends on its processing conditions. The $\alpha$-crystal is the most stable form [2], the hexagonal $\beta$-crystal is formed by a special nucleating agent [3], and the orthorhombic $\gamma$-crystal phase is formed under high-pressure [4]. In addition, a so-called mesophase, also known as smectic or semicrystalline phase, is formed by quenching of the melt or by mechanical deformation of $\alpha$-crystal containing samples [5]. Nishida et al. reported the effect of stereoregularity on mesophase formation and revealed the need for a certain stereoregularity [6]. The mesophase was transformed into an $\alpha$-crystal by heating, and the transformation mechanism was proposed by Jiang et al [7].

Because of its low density, low environmental burden, and good melt-processability, PP products are widely used as moldings, films, and fibers. In particular, PP fiber is used industrially in applications, such as ropes for marine products, spun-bonding nonwoven fabrics, and carpets. PP fiber is generally produced by melt-spinning, drawing, and annealing processes. Importantly, two crystal orientation forms are observed for melt-spun fibers, that is, the $a^{*}$-axis orientation observed for low orientation fibers and the c-axis orientation observed for high orientation fibers. Under a continuous drawing process, a higher order structure formed in the melt-spinning process is considered to be broken under the steep yielding of the so-called necking. After the necking, the fiber structure, composed of alternately aligned highly oriented crystalline and amorphous phases, develops instead. The strength and Young's modulus of the fiber greatly increase as the fiber structure develops in the drawing process. The melt-spinning conditions

\# corresponding author: Yutaka Ohkoshi (E-mail: yokoshi@shinshu-u.ac.jp, Tel: +81-75-724-7562) 
also affect these properties of drawn fibers. For example, Guillaume et al. found a relationship between fiber strength and crystal orientation of asspun fibers made under different melt-spinning conditions [8]. The molecular network structure formed in the melt-spinning process constrained the fiber structure reconstruction in the drawing process, and then constrained the strength of the drawn fibers. In this study, we considered the crystal orientation form of the melt-spun fiber to evaluate the molecular network structure formed in the melt-spinning process.

Unlike ordinary drawing processes, laser-heated drawing enables super-stable neck-drawing with a small neck-point deviation (of the same order as the fiber diameter) because laser beam irradiation heats the running fiber far more rapidly and uniformly than heat transfer heating through the fiber surface [9-11]. Therefore, the X-ray diffraction patterns, which are obtained using this drawing method and a highluminance synchrotron X-ray source, enable analysis of fiber structure development after the neckdrawing. There have been many reports [12-26] on the fiber structure development of polymers observed by this method. The fiber structure development of PP at a time-resolution of $0.4 \mathrm{~ms}$ was also reported by Kang et al. [12]. This report, revealed that the $\alpha$-crystal and long-period structure of the asspun fiber disappeared less than $0.4 \mathrm{~ms}$ after necking, and developed again afterwards; however, because of insufficient time-resolution, the timing of the disappearance was not clear. Specifically, it was not clear if the structure disappeared at the point of necking or after the necking. Macroscopic deformation of necking is typically almost completed within $0.1 \mathrm{~ms}$, whereas the reconstruction of the higher-order structure starts with necking, and it requires more than several milliseconds in most cases. The above-mentioned effects of melt-spinning conditions on the drawn fiber strength indicate that melt-spinning conditions affect the reconstruction. Thus, we can approach fiber strength development by analyzing the effects of melt-spinning conditions on the reconstruction. Such measurements are now possible owing to the 0.1-0.2-ms time-resolution obtainable with the use of an undulator equipped synchrotron X-ray source [22-26]. In this study, we used such an X-ray source to analyze the effects of crystal orientation form of melt-spun fiber on the fiber structure development after necking.

\section{Experimental}

\subsection{Materials}

The fibers used for drawing were prepared by melt-spinning of PP (Japan Polypropylene Corporation SA03, Melt Flow Ratio $30 \mathrm{~g} / 10 \mathrm{~min})$. The polymer was heated at $215{ }^{\circ} \mathrm{C}$, extruded from a one-hole nozzle at a mass flow rate of $3.3 \mathrm{~g} / \mathrm{min}$, and taken-up at 400 $1200 \mathrm{~m} / \mathrm{min}$. The nozzle diameter was $0.7 \mathrm{~mm}$, and the length/diameter ratio was 3 .

\subsection{On-line Measurement}

Schematic diagram of the measuring system is shown in Fig. 1. Fibers were drawn continuously based on the speed difference between the feed and take-up rollers under heating by $\mathrm{CO}_{2}$ laser irradiation. The draw ratio was determined so that the drawing stress was approximately $100 \mathrm{MPa}$. A random polarized laser beam with a wavelength of $10.6 \mu \mathrm{m}$ and a $6-\mathrm{mm}$ spot diameter was generated by a PIN-30 $\mathrm{R}$ laser (Onizuka Glass Co., Ltd.) and irradiated on to the running fiber from three different directions. The laser power $\left(L_{\mathrm{p}}\right)$ for each drawing condition was determined so as to minimize the fluctuations of the neck-drawing point. The drawing tension was measured by a tension meter (HS-1500 S, Eiko Sokki Co., Ltd.) with a 1-N pickup installed between the neck-drawing point and the take-up roller. The

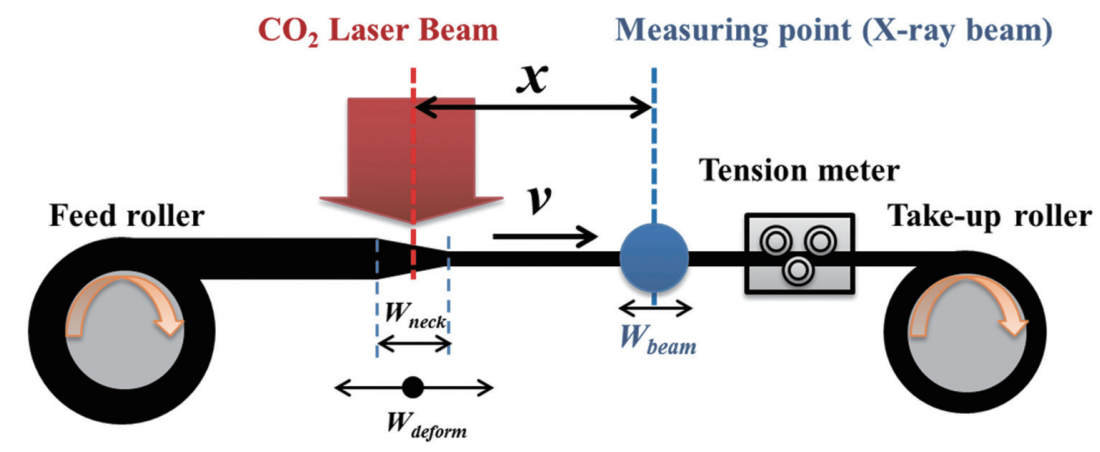

Fig. 1 Schematic diagram of the measurement system. 
Table 1 Drawing conditions.

\begin{tabular}{cccccc}
\hline $\begin{array}{c}\text { Spinning speed } \\
/ \mathrm{m} \mathrm{min}^{-1}\end{array}$ & Draw ratio & $\begin{array}{c}\text { Take-up speed* } \\
/ \mathrm{m} \mathrm{min}^{-1}\end{array}$ & $\begin{array}{c}\text { Laser power } \\
/ \mathrm{W}\end{array}$ & $\begin{array}{c}\text { Drawing stress } \\
/ \mathrm{MPa}\end{array}$ & $\begin{array}{c}\text { Time resolution } \\
/ \mathrm{ms}\end{array}$ \\
\hline 400 & 5.3 & 60 & 11 & $97 \pm 4$ & 0.19 \\
800 & 3.8 & & 11 & $95 \pm 4$ & 0.33 \\
1200 & 3.0 & 120 & 26 & $98 \pm 5$ & 0.34 \\
\hline
\end{tabular}

* After necking

drawing stress was calculated from the drawing tension and the diameter of the drawn fiber. The drawing conditions are listed in Table 1.

Wide-angle X-ray diffraction and small-angle Xray scattering patterns (WAXD/SAXS) were simultaneously taken with the X-ray beam irradiated onto the running fiber. X-ray images were acquired at time points after necking by changing the distance $(x)$ between the X-ray irradiation point and necking point. The distance changed with the necking point by moving the laser irradiation position. The elapsed time after necking was calculated from the distance $(x)$ divided by the fiber running speed $(v)$. In particular for elapsed times less than $1.0 \mathrm{~ms}$, the distance was measured accurately from video images taken during the measurement. The video images were acquired from the direction coaxial to the X-ray beam with a video camera (Watec Co., Ltd. WAT-232S type) equipped with a telecentric lens (OPTART Co., Ltd. TV-2S) with $2 \times$ magnification. In addition to the average position of the necking point, we also determined its fluctuation width $\left(W_{\text {deform }}\right)$ from 10 still images taken from the video. The synchrotron X-ray beam of SPring-8 BL03XU (FSBL) was used in this study. An undulator was equipped to obtain ultrahighintensity X-ray beams. The wavelength of the X-ray beam was $0.10 \mathrm{~nm}$ and the beam dimensions were $50 \mu \mathrm{m} \times 40 \mu \mathrm{m}$ parallel and perpendicular to the fiber running direction, respectively. The camera lengths for wide-angle and small-angle measurements were 91.8 and $1780 \mathrm{~mm}$, and the detectors used each measurement were flat panel detector $(1032 \times$ 1032 pixels) and CCD $(672 \times 512$ pixels), respectively. The time resolution of the measurements was calculated from the fiber speed $(v)$ and the position resolution, which was calculated from the length of the necking point $(0.10-0.38 \mathrm{~mm})$, width of the X-ray beam $(0.050 \mathrm{~mm})$, and the above-mentioned fluctuation width $(0.15-0.56 \mathrm{~mm})$ of necking point. The obtained time resolutions are also listed in Table 1 . The WAXD/SAXS patterns of drawn fiber were also measured under the equivalent stress applied at drawing.

\subsection{Birefringence}

Birefringence for each fiber was measured on a polarized microscope (BX51-33POC, Olympus Co. Ltd.). Tricresyl phosphate was used as the immersion oil. The average and standard deviation of the birefringence were calculated for 10 samples.

\subsection{Tensile testing}

The tensile testing was performed with an Autograph AGS-X, Shimadzu Co. Ltd. equipped with a 50-N load cell. The sample length and elongation rate were $40 \mathrm{~mm}$ and $100 \% / \mathrm{min}$, respectively. The average and standard deviation of the strength, elongation, and Young's modulus were calculated for every ten samples. The Young's modulus was determined from data in the range of $0.1 \%-1.0 \%$ strain.

\subsection{Differential scanning calorimetry (DSC)}

DSC was performed on a calorimeter (Thermoplus DSC8230, Rigaku Co. Ltd.) at a heating rate of $10 \mathrm{~K} / \mathrm{min}$. Short cut fibers were used as samples for the DSC measurements. The crystallinity was determined from the heat of fusion. The heat of fusion of a PP crystal $(209 \mathrm{~kJ} / \mathrm{kg})$ was used for the calculations.

\section{Results and Discussion}

\subsection{Structure and tensile properties}

Birefringence, crystallinity, and tensile properties of as-spun and drawn fibers are listed in Table 2. The birefringence and strength of the as-spun fiber increased as the take-up speed was increased. Conversely, the tensile strength and Young's modulus of fibers drawn under almost the same drawing stress decreased as the take-up speed was increased.

\subsection{Temperature profile}

The fiber temperature profile along the fiber drawing-line was estimated by the energy balance formula considering the heating by laser-beam irradiation, heating by plastic deformation, and cooling by heat transfer. We assumed that all work applied at the necking changed the heat with the plastic deformation. We also assumed Gaussian-type intensity profile of irradiated laser beam, and heat 
Table 2 Structure and tensile properties of as-spun and drawn PP fibers.

\begin{tabular}{|c|c|c|c|c|c|c|}
\hline Sample & $\begin{array}{l}\text { Spinning speed } \\
/ \mathrm{m} \mathrm{min}^{-1}\end{array}$ & $\Delta n \times 10^{3}$ & $\begin{array}{c}X_{\mathrm{DSC}} \\
/ \%\end{array}$ & $\begin{array}{c}\text { Tensile strength } \\
/ \mathrm{MPa}\end{array}$ & $\begin{array}{c}\text { Elongation at break } \\
\qquad / \%\end{array}$ & $\begin{array}{c}\text { Young's modulus } \\
\text { /GPa }\end{array}$ \\
\hline \multirow{3}{*}{ As-spun } & 400 & $5.0 \pm 0.2$ & 39 & $66 \pm 4$ & $840 \pm 60$ & $1.3 \pm 0.1$ \\
\hline & 800 & $7.2 \pm 0.2$ & 32 & $93 \pm 4$ & $660 \pm 40$ & $1.4 \pm 0.1$ \\
\hline & 1200 & $13.5 \pm 0.1$ & 37 & $108 \pm 6$ & $480 \pm 40$ & $1.2 \pm 0.1$ \\
\hline \multirow{3}{*}{ Drawn } & 400 & $32 \pm 1$ & 43 & $426 \pm 8$ & $92 \pm 7$ & $4.3 \pm 0.2$ \\
\hline & 800 & $29 \pm 1$ & 41 & $390 \pm 10$ & $105 \pm 8$ & $3.5 \pm 0.2$ \\
\hline & 1200 & $29 \pm 2$ & 39 & $350 \pm 10$ & $107 \pm 5$ & $3.0 \pm 0.2$ \\
\hline
\end{tabular}

transfer coefficient was estimated with the equation proposed by Kase and Matsuo [27]. The estimation had ascertained by the temperature measurement using infrared thermometer [28]. No latent heat of melting and crystallization were considered in this study. Because the $X_{\mathrm{DSC}}$ listed in Table 2 did not change so much by drawing, their effect on the fiber temperature was restrictive. However, they can affect the rate of micro-fibril structure reconstruction as discussed in section 3.3 and 3.4, that is, the temporal hating by crystal melting can accelerate the recrystallization.

The estimated fiber temperature profile is shown in Fig. 2, where the horizontal axis indicates the distance from laser beam axis. The laser irradiation area corresponding to the laser beam diameter is also shown in the figure. The laser beam irradiation increased the fiber temperature to be in the range of $50-70^{\circ} \mathrm{C}$ and plastic deformation increased the temperature sharply to $100-130^{\circ} \mathrm{C}$, and then the surrounding air cooled the fiber gradually. Higher fiber temperatures were estimated for the fiber spun at lower take-up speeds. In particular at $400 \mathrm{~m} / \mathrm{min}$,

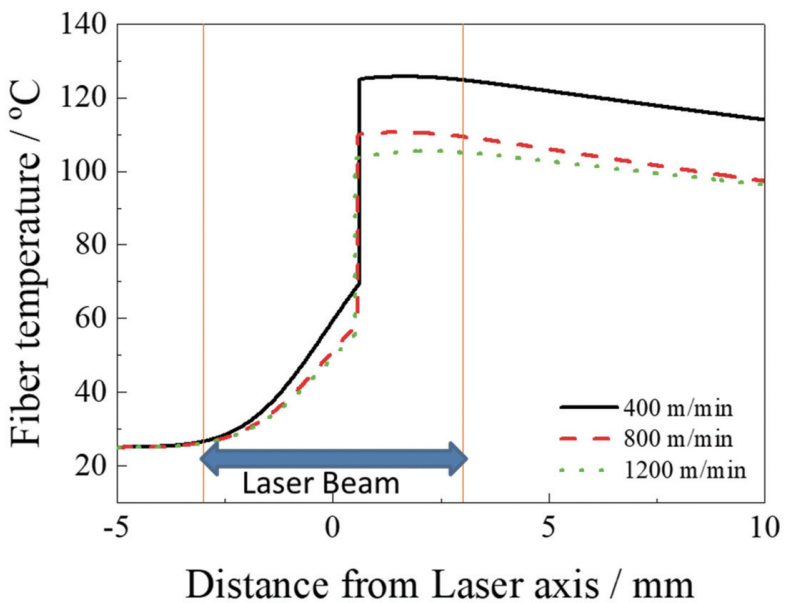

Fig. 2 Estimated fiber temperature profiles. Spinning speeds are noted in the figure. we estimated the fiber temperature to be $20 \mathrm{~K}$ higher than those at 800 and $1200 \mathrm{~m} / \mathrm{min}$. The higher fiber temperature is attributed to the higher draw ratio. A higher draw ratio increases the applied work at the plastic deformation under the same drawing stress. A higher draw ratio also increases the fiber temperature by increasing the irradiated laser energy as the fiber running speed decreases, while almost maintaining the location of neck-drawing point. This effect occurs because the take-up speed is maintained constant, while the fiber running speed before the neck-drawing point decreases as the draw ratio is increased.

\subsection{Wide angle X-ray diffraction}

A part of the obtained WAXD patterns are shown in Fig. 3. The patterns were converted to diffraction angle - inclination angle diagrams, as shown in Fig. 4. The inclination angle $\delta$ is almost identical to the azimuthal angle $\phi$ except for in the (a)

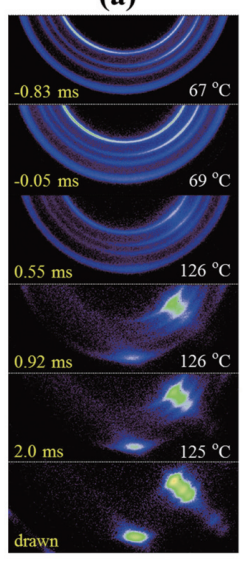

(b)

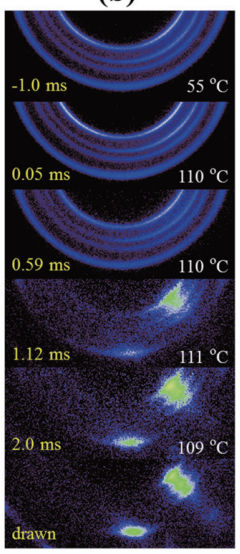

(c)

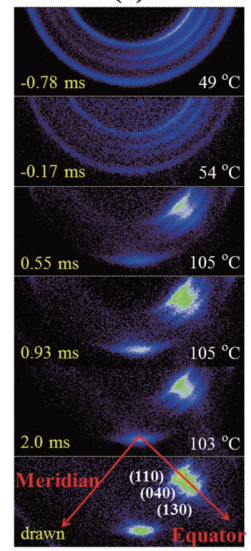

Fig. 3 WAXD patterns taken at the certain elapsed time after necking. Elapsed time and estimated fiber temperature are shown in each image. Spinning speeds are (a) $400 \mathrm{~m} / \mathrm{min}$, (b) $800 \mathrm{~m} / \mathrm{min}$, and (c) $1200 \mathrm{~m} / \mathrm{min}$. Meridian and equator directions are shown in the bottom right image. 
(a)

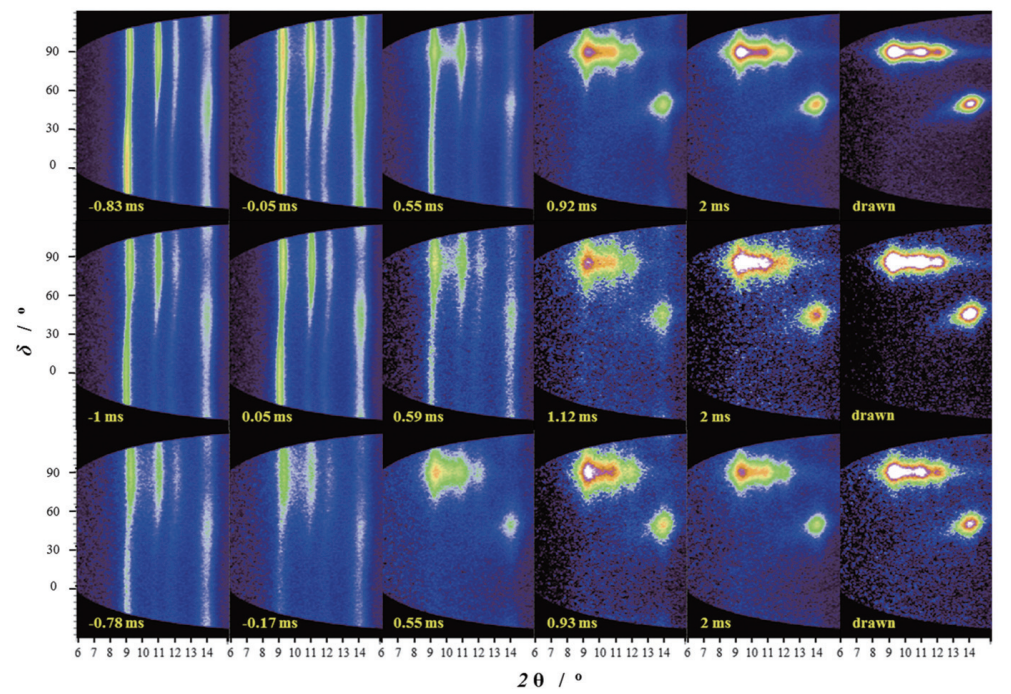

Fig. 4 Converted WAXD patterns for each elapsed time as shown in Fig. 2. Horizontal and vertical axes indicate the diffraction angle $(2 \theta)$ and inclination angle $(\delta)$, respectively. Spinning speeds are (a) $400 \mathrm{~m} / \mathrm{min}$, (b) $800 \mathrm{~m} / \mathrm{min}$ and (c) $1200 \mathrm{~m} / \mathrm{min}$.

vicinity of the meridional direction because of the relationship $\cos \phi=\cos \theta \cdot \cos \delta$ in which $2 \theta$ is the diffraction angle. The numerical value noted for each pattern is the elapsed time after necking; hence, negative values indicate patterns acquired before necking. Clear (110), (040), and (130) $\alpha$-crystal diffraction features were observed for WAXD pattern of all as-spun fibers. However, the orientation form was clearly different for the as-spun fibers at 400 and $1200 \mathrm{~m} / \mathrm{min}$. That is, the equatorial orientation of the above three diffraction features for $1200 \mathrm{~m} / \mathrm{min}$ indicated a c-axis orientation to the fiber axis, whereas the near-meridional (110) diffraction observed at 400 $\mathrm{m} / \mathrm{min}$ indicated the $\mathrm{a}^{*}$-axis orientation. Thus, more $\mathrm{a}^{*}$-axis oriented crystallites were mixed with c-axis oriented crystallites at $400 \mathrm{~m} / \mathrm{min}$. The $800 \mathrm{~m} / \mathrm{min}$ pattern was intermediate between these but was rather similar to that at $400 \mathrm{~m} / \mathrm{min}$. Remarkably, the peak diffraction angle of the (110) diffraction was different between the orientation forms, that is, the peak diffraction angle at approximately $9.1^{\circ}$ for the near-meridional direction was clearly smaller than the 9.3 $3^{\circ}$ for the equatorial direction (also see Fig. 5). This difference indicates that the packing of the $\mathrm{a}^{*}$-axis oriented crystallite is lower than that of c-axis oriented crystallite.

Low-oriented diffraction features were observed for all as-spun fibers disappeared within $1.0 \mathrm{~ms}$, and highly c-axis oriented diffraction features appeared from $0.5 \mathrm{~ms}$. The changes of the azimuthal profile of the $400 \mathrm{~m} / \mathrm{min}$ fiber are shown in Fig. 5 . The $\mathrm{a}^{*}$-axis oriented diffraction observed in the $9.1^{\circ}$ profile (a) almost disappeared at $0.55 \mathrm{~ms}$, and the highly c-axis
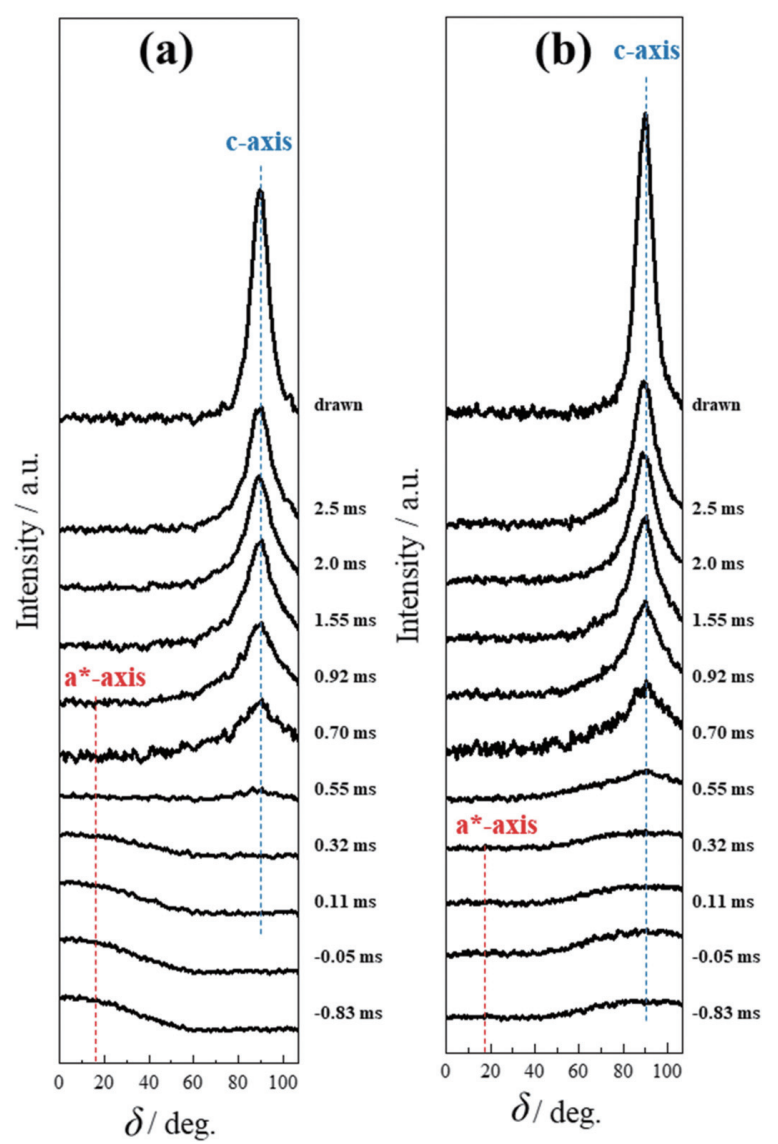

Fig. 5 Intensity profiles along the inclination angle for the fiber spun at $400 \mathrm{~m} / \mathrm{min}$. Diffraction angles of (a) $9.1^{\circ}$ and (b) $9.3^{\circ}$ are the peak positions of (110) diffraction for $\mathrm{a}^{*}$-axis and caxis orientated crystallites. Corresponding peak position for each orientation form and the elapsed times are shown in the figure.

oriented diffraction appeared at the same time. The peak diffraction angle of the newly appeared c-axis oriented diffraction was approximately $9.3^{\circ}$. Dissipation of low-oriented diffraction features and 
the appearance of high-oriented diffraction features were observed at an earlier timing for the fiber spun at higher speed; that is, for $1200 \mathrm{~m} / \mathrm{min}$, the loworiented diffraction disappeared at $0.17 \mathrm{~ms}$ and a highoriented diffraction feature appeared at $0.34 \mathrm{~ms}$ after necking.

For more quantitative analysis, changes in the crystal, mesophase, and amorphous fractions were estimated from the obtained WAXD patterns. After integrating the intensity along the inclination angle to cancel the orientation effect, $s^{2}$ was multiplied to compensate for the Lorentz factor, where $s=2 \sin \theta / \lambda$ is the magnitude of the scattering vector determined from the diffraction angle $(2 \theta)$ and the X-ray wavelength $(\lambda)$. One of the obtained profiles is shown in Fig. 6. Five $\alpha$-crystal diffractions such as (110), (040), (130), (111), and (-131); two mesophase diffractions; and an amorphous halo should be overlaid on this profile. However, because the (111) and (-131) diffraction peaks are difficult to separate from the higher angle mesophase diffraction features, we did not distinguish them and excluded them from the fraction estimation. The profile was fitted based on the peaks assuming a Gaussian profile, as shown in equation (1).

$$
I(s)=I_{0} \exp \left\{-4 \ln 2 \times\left(\frac{s-s_{0}}{\beta}\right)^{2}\right\},
$$

where $I_{0}, s_{0}$, and $\beta$ are the intensity, position, and halfwidth of each peak, respectively. Some studies have reported the peak position and peak width of the mesophase diffraction features and the amorphous

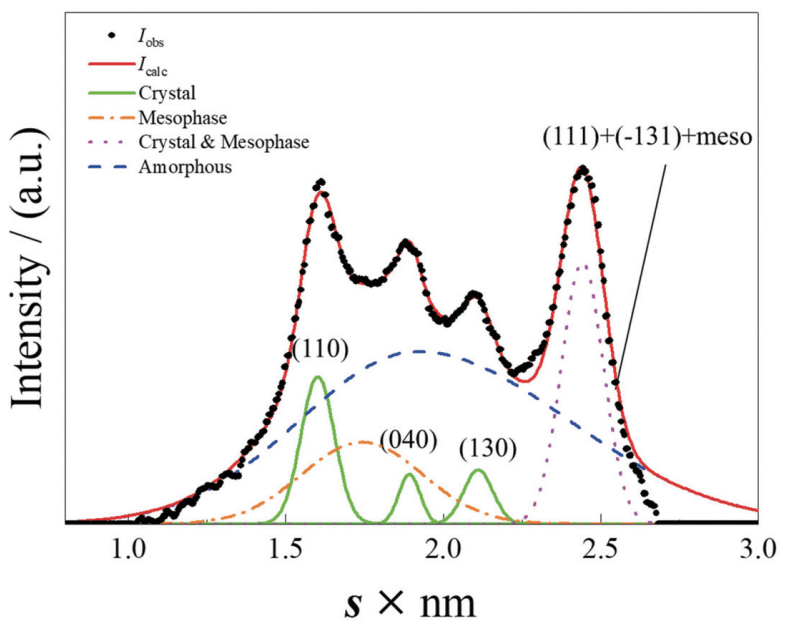

Fig. 6 Measured $\left(I_{\mathrm{obs}}\right)$ and fitted $\left(I_{\text {calc }}\right)$ WAXD profiles. Spinning speed is $400 \mathrm{~m} / \mathrm{min}$, and the elapsed time after necking is $2.0 \mathrm{~ms}$. Fitting curves for crystalline, mesophase, and amorphous peaks are also shown. halo $[1,6,7]$. In this study, we fixed the peak position and peak width of the lower-angle mesophase diffraction to be 1.74 and $0.45 \mathrm{~nm}^{-1}$, respectively, and also fixed the peak position and peak widths of an asymmetrical amorphous halo profile, that is, the peak position, lower-side peak width, and higher-side peak width were fixed at 1.92, 0.87, and $1.21 \mathrm{~nm}^{-1}$, respectively. All the obtained profiles were fitted well under these assumptions. The fractions were estimated by integrating the obtained profiles of $1.22<s<2.26 \mathrm{~nm}^{-1}$, and these results are plotted against the elapsed time in Fig. 7. The mesophase fractions for all fibers clearly increased after necking, and they subsequently decrease a little until reaching the drawn state. In contrast, the crystal fraction of 400 $-800 \mathrm{~m} / \mathrm{min}$ fibers decreased after necking and showed a small increase subsequently. The $1200 \mathrm{~m} / \mathrm{min}$ fiber showed a clear earlier increase of mesophase fraction after necking than those of 400$800 \mathrm{~m} / \mathrm{min}$ fibers. In addition, the amorphous fraction of the $1200-\mathrm{m} / \mathrm{min}$ fiber tended to decrease after necking, whereas those fractions of the 400-800-m/min fibers were increased after necking. These results indicate that the structures of the $400-800 \mathrm{~m} / \mathrm{min}$ fibers were destabilized by the necking, whereas that of the $1200 \mathrm{~m} / \mathrm{min}$ fiber was stabilized by the necking.

The above results are consistent with the estimation of Kang et al [12] that low-oriented crystals obtained by melt-spinning should change to a highly oriented mesophase by necking. Furthermore, it was predicted that the high-oriented crystals of the drawn

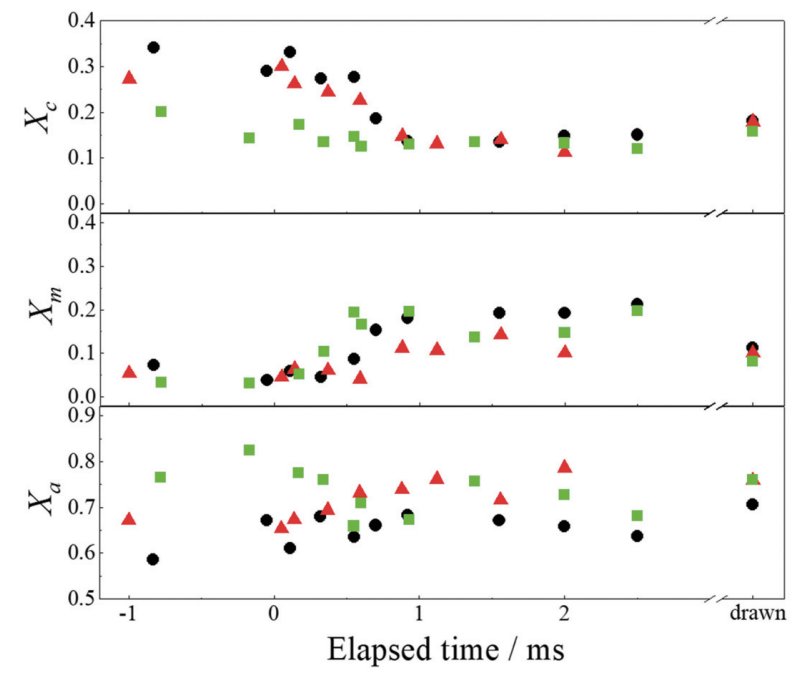

Fig. 7 Integrated intensity fraction of crystal $\left(X_{c}\right)$, mesophase $\left(X_{m}\right)$, and amorphous $\left(X_{a}\right)$ peaks. The spinning speeds are $(\mathbf{O}) 400 \mathrm{~m} / \mathrm{min},(\boldsymbol{\Delta}) 800 \mathrm{~m}$ $/ \mathrm{min}$ and $(\square) 1200 \mathrm{~m} / \mathrm{min}$. 
fiber should be restructured from the highly oriented mesophase and amorphous phases. However, the above results reveal that fracturing of the loworiented crystal and restructuring of the highoriented crystal did not occur just after necking but did occur at some time after necking. In particular for the $400-800 \mathrm{~m} / \mathrm{min}$ fibers, the process started at $0.5 \mathrm{~ms}$ after necking, and finished at almost $1.0 \mathrm{~ms}$ after necking. This time-lag is clearly longer than the time-resolution of this measurement and an order of magnitude longer than the time for necking. Therefore, in particular for the fiber spun at lowerspeed, it becomes clear that the low-oriented crystal survives for some time after the breakage of macroscopic structures at necking.

\subsection{Small angle X-ray scattering}

A part of the obtained SAXS patterns are shown in Fig. 8. The meridional peak of the long-period was observed for all the as-spun fibers. However, contrary to the two-point pattern observed for the $1200 \mathrm{~m} / \mathrm{min}$ fiber, a ring-like pattern was overlaid on the two-point pattern for the $400 \mathrm{~m} / \mathrm{min}$. Hence, the latter fiber contains a low-oriented long-period structure in addition to a c-axis-oriented one. The long-period peak of the as-spun fibers vanished several hundreds of microseconds after necking, and the highly oriented two-points pattern of the longer long-period appeared immediately afterwards. The fiber spun at lower speed required a longer time for the pattern change. To analyze the pattern changes more quantitatively, the meridional SAXS profiles were fitted by a Gaussian curve as defined in equation (1). Fig. 9 shows the long period $\left(L=1 / s_{0}\right)$ and its normalized width $\left(\beta / s_{0}\right)$ calculated from the obtained peak position $\left(s_{0}\right)$ and peak width $(\beta)$. The long period clearly increased after the notably decrease of scattering intensity. The normalized width also increased at the sharp decrease of scattering intensity and it gradually decreased thereafter.

The dissipation of the long-period pattern almost coincided with the dissipation of the low-oriented crystal diffraction. Furthermore, the decrease of the normalized width also coincided with the increase of high-oriented mesophase. However, the pattern change was more pronounced than that of WAXD. This result indicated that the original long-period structure was destroyed after a certain portion of the low-oriented crystal was destroyed. Additionally, the result suggests that the regularity of the newly developed long-period structure was simultaneously improved with the mesophase development.

In particular for the lower-speed-spun fibers, an almost 1-ms delay of the pattern change after necking was observed in both the WAXD and SAXS measurements. It is unclear why the low-speed spun fibers require a longer time for the structural change,

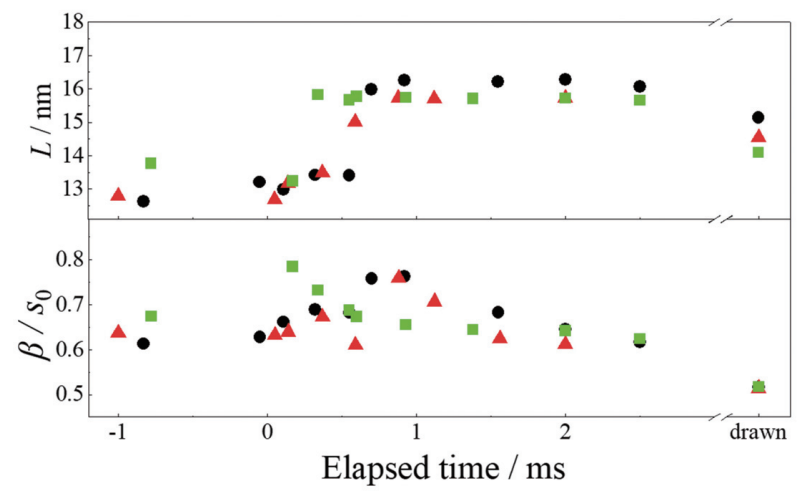

Fig. 9 Long-period $(L)$ and normalized peak width along the meridian. Spinning speeds are (O) $400 \mathrm{~m} / \mathrm{min}, \quad(\boldsymbol{A}) \quad 800 \mathrm{~m} / \mathrm{min}$, and (ロ) $1200 \mathrm{~m} / \mathrm{min}$.

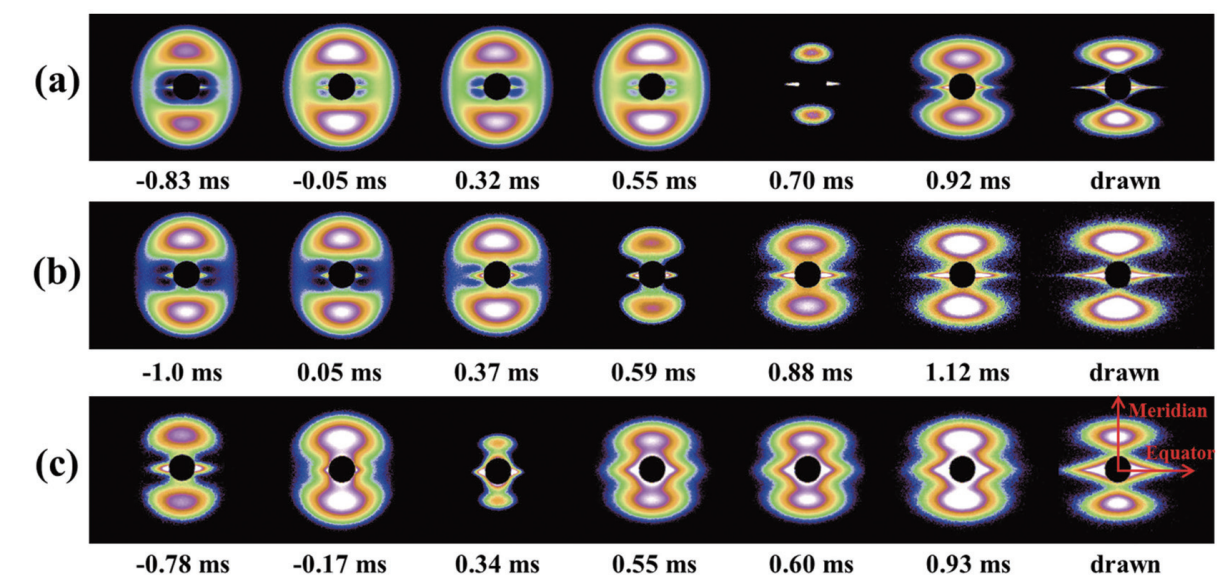

Fig. 8 SAXS patterns taken at the certain elapsed time after necking. Elapsed time is shown in each image. Spinning speeds are (a) $400 \mathrm{~m} / \mathrm{min}$, (b) $800 \mathrm{~m} / \mathrm{min}$, and (c) $1200 \mathrm{~m} / \mathrm{min}$. Meridian and equator directions are shown in the bottom right image. 
even at the same drawing stress, larger draw ratio, and higher fiber temperature. Because of the similar birefringence of the drawn fiber, the effect of the average molecular orientation is unlikely. The greater crystallinity of the lower-speed-spun fibers might be attributed to the long time for breakdown of the structure. In addition, the SAXS pattern of the 1200-m /min fiber changed slightly before the change in WAXD, whereas the change in WAXD preceded the change in SAXS for the lower speed spun fiber. The preceding change in the WAXD results indicates a blocking effect of the $a^{*}$-axis oriented crystal on the long-period breakdown. As shown in 3.3, the $\mathrm{a}^{*}$-axis oriented crystal was unstable because of its larger $d$ spacing than that of c-axis oriented crystal but its proportion was greater than that of c-axis oriented crystal. Despite the unstable structure, the greater portion of a*-axis oriented crystal lamellae should bear the external force to survive a long-period structure for a certain time.

After break-down of the $a^{*}$-oriented crystallites, a higher drawing stress should be concentrated over a smaller portion of the c-axis oriented long-period structure of the lower-speed spun fibers. This hypothesis is supported by the longer long-period of drawn fiber. Notably, a higher tensile strength and higher modulus were obtained for the lower-speed spun and drawn fiber regardless of the stress being concentrated over a smaller portion of the long-period structure. To explain this inconsistency, the larger structure should also be taken into consideration. As discussed above, the long-period structure or microfibril structure was clearly reconstructed after the necking, at which point the macroscopic fibril structure formed. Tomisawa et al [25, 26] suggested that the macroscopic fibril structure formed at the necking point decided the strength and modulus of the resultant fiber because the micro-fibril of poly (ethylene terephthalate) (PET) have sufficiently high orientation and modulus, and the amount and orientation of inter-microfibrillar tie-chains formed in the macroscopic fibril structure should govern the tensile properties of the fiber. Similar to PET fibers, the structure formed under the applied work at necking (i.e., the macroscopic fibril structure) should also explain the tensile properties of PP fibers.

\section{Conclusion}

PP fibers prepared at a spinning speed of $400-$
$1200 \mathrm{~m} / \mathrm{min}$ were continuously drawn with laser heating under the same drawing stress, and the fiber structure development on the drawing process was analyzed by the WAXD/SAXS images with a time resolution of $0.19-0.34 \mathrm{~ms}$. Whereas a*-axis oriented crystal and low oriented long-period structures formed at lower speeds, c-axis oriented crystal and highly oriented long-period structures formed at higher speed. The long-period structure and loworiented crystal survived for several hundreds of microseconds after the macroscopic structure breakage at necking, and the highly c-axis oriented long-period structure and mesophase reconstructed after the breakdown. A longer time for the structural change was required for the lower speed spun fibers, which can be explained by the stress bearing of the surviving $\mathrm{a}^{*}$-axis oriented crystal for a certain time after necking. In addition to the micro-fibril structure discussed above, the macroscopic fibril structure formed under the applied work at necking should be considered to explain the higher tensile strength and modulus of the low-speed spun and drawn fibers.

\section{Acknowledgment}

This study was supported by Grants-in-Aid for Scientific Research (JP16K05910 and JP19K0559700) from the Ministry of Education and Science Ministry, Japan. Experiments were performed at the SPring-8 synchrotron radiation facility (No. 2014B7263). We also thank Andrew Jackson, PhD, from Edanz Group (www.edanzediting.com/ac) for editing a draft of this manuscript.

\section{References}

1. G. Natta, P. Pino, P. Corradini, F. Danusso, E. Mantica, G. Mazzanti, G. Moraglio et al., J. Am. Chem. Soc., 77, 1708-1710 (1955). https://doi.org/10.1021/ja01611a109.

2. M. Hikosaka, T. Seto, Polymer Journal, 5, 111-127 (1973). https://doi.org/10.1295/polymj.5.111.

3. J. Kotek, M. Raab, J. Baldrian, W. Grellmann, $J$. Polym. Sci., 85, 1174-1184 (2002). https://doi.org/10.1002/app.10701.

4. B. Lotz, J. C. Wittmann, Polymer, 37, 4979-4992 (1996).

https://doi.org/10.1016/0032-3861(96)00370-9.

5. I. Coccorullo, R. Pantani, G. Titomanlio, Polymer, 
44, 307-318 (2003). https://doi.org/10.1016/S 0032-3861(02)00762-0.

6. T. Konishi, K. Nishida, T. Kanaya, K. Kaji, Macromolecules, 38, 8749-8754 (2005). https://doi.org/10.1021/ma 050908f.

7. Q. Jiang, Y. Zhao, C. Zhang, J. Yang, Y. Xu, D. Wang, Polymer, 105, 133-143 (2016). https://doi.org/10.1016/j.polymer.2016.10.004.

8. G. Colombe, S. Gree, O. Lhost, M. Dupire, M. Rosenthal, D. A. Ivanov, Polymer, 52, 5630-5643 (2011). https://doi.org/10.1016/j.polymer.2011.09.035.

9. T. Ikaga, A. Kobayashi, Y. Ohkoshi, Y. Gotoh, M. Nagura, H. Urakawa, K. Kajiwara, Sen'i Gakkaishi, 58, 8-15 (2002). https://doi.org/10.2115/fiber.58.8

10. T. Ikaga, A. Kobayashi, Y. Ohkoshi, Y. Gotoh, M. Nagura, Sen 'i Gakkaishi, 58, 16-21 (2002). https://doi.org/ 10.2115/fiber.58.16

11. W. Okumura, Y. Ohkoshi, Y. Gotoh, M. Nagura, $J$. Polym. Sci., Part B: Polym. Phys., 41, 2322-2331 (2003). https://doi.org/10.1002/polb.10467.

12. Y. A. Kang, K. H. Kim, S. Ikehata, Y. Ohkoshi, Y. Gotoh, M. Nagura, H. Urakawa, Polymer, 52, 20442050 (2011). https://doi.org/10.1016/j.polymer.2011.03.005.

13. K. H. Kim, Y. A. Kang, A. Yokoyama, T. Ikaga, Y. Ohkoshi, I. Wataoka, H. Urakawa, Polymer Journal, 44, 1030-1035 (2012). https://doi.org/10.1038/pj.2012.65.

14. Y. A. Kang, K. H. Kim, S. Ikehata, Y. Ohkoshi, Y. Gotoh, M. Nagura, M. Koide, H. Urakawa, Polymer Journal, 42, 657-662 (2010). https://doi.org/10.1038/pj.2010.53.

15. T. Yamaguchi, K. H. Kim, T. Murata, M. Koide, S. Hitoosa, H. Urakawa, Y. Ohkoshi, Y. Gotoh, M. Nagura, M. Kotera, K. Kajiwara, J. Polym. Sci., Part B: Polym. Phys., 46, 2126-2142 (2008). https://doi.org/10.1002/polb.21546.

16. K. H. Kim, T. Yamaguchi, Y. Ohkoshi, Y. Gotoh, M. Nagura, H. Urakawa, M. Kotera, T. Kikutani, J. Polym. Sci., Part B: Polym. Phys., 47, 1653-1665 (2009). https://doi.org/10.1002/polb.21769.

17. K. H. Kim, Y. A. Kang, T. Murata, S. Ikehata, Y. Ohkoshi, Y. Gotoh, M. Nagura, M. Koide, H. Urakawa, M. Kotera, Polymer, 49, 5705-5713 (2008). https://doi.org/10.1016/j.polymer.2008.10.022.
18. K. H. Kim, R. Aida, Y. A. Kang, T. Ikaga, Y. Ohkoshi, I. Wataoka, H. Urakawa, Polymer, 53, 4272-4279 (2012). https://doi.org/10.1016/j.polymer.2012.07.043.

19. K. Ide, T. Ikaga, Y. Ohkoshi, I. Wataoka, M. Masuda, Y. Maeda, Sen’i Gakkaishi, 70, 76-83 (2014). https://doi.org/10.2115/fiber.70.76.

20. K. H. Kim, Y. Ohkoshi, A. Wakasugi, A. Komoriya, T. Ikaga, I. Wataoka, H. Urakawa, M. Masuda, Y. Maeda, J. Fiber Sci. Technol., 73, 19-26 (2017). https://doi.org/10.2115/fiberst.fiberst.2017-0003.

21. G. Matsuno, T. Ikaga, K.H. Kim, Y. Ohkoshi, T. Tajima, H. Yamaguchi, I. Wataoka, J. Fiber Sci. Technol., 73, 158-169 (2017). https://doi.org/10.2115/fiberst.2017-0023.

22. K. Sugawara, T. Ikaga, K. H. Kim, Y. Ohkoshi, K. Okada, H. Masunaga, T. Kanaya, M. Masuda, Y. Maeda, Polymer, 79, 37-46 (2015). https://doi.org/10.1016/j.polymer.2015.10.006.

23. R. Tomisawa, T. Ikaga, K. H. Kim, Y. Ohkoshi, K. Okada, H. Masunaga, T. Kanaya, M. Masuda, Y. Maeda, Polymer, 116, 357-366 (2017). https://doi.org/10.1016/j.polymer.2016.12.071.

24. R. Tomisawa, T. Ikaga, K. H. Kim, Y. Ohkoshi, K. Okada, H. Masunaga, T. Kanaya, M. Masuda, Y. Maeda, Polymer, 116, 367-377 (2017). https://doi.org/10.1016/j.polymer.2016.12.077.

25. R. Tomisawa, S. Oneda, T. Ikaga, K. H. Kim, Y. Ohkoshi, K. Okada, H. Masunaga, T. Kanaya, H. Katsuta, Y. Funatsu, Polymer, 164, 163-173 (2019). https://doi.org/10.1016/j.polymer.2019.01.002.

26. R. Tomisawa, T. Ando, T. Ikaga, K. H. Kim, Y. Ohkoshi, K. Okada, H. Masunaga, T. Kanaya, H. Katsuta, Y. Funatsu, Polymer Journal, 51, 211-219 (2019). https://doi.org/10.1038/s41428-018-0143-6

27. S. Kase, T. Matsuo, J. Polym. Sci., 3, 2541-2554 (1965). https://doi.org/10.1002/pol.1965.100030712

28. W. Okumura, T. Yamaguchi, Y. Ohkoshi, Y. Gotoh, M. Nagura, International Polymer Processing, 17, 124-132 (2002). https://doi.org/10.3139/217.1684 